\title{
TECHNICAL AND ECONOMIC STUDY ON CLEANING THE COOLING CHANNELS OF A PLASTIC INJECTION MOLD
}

\author{
Florin Iounaș ${ }^{1}$, Dănuț Iounaș ${ }^{1}$, Alina Bianca Pop ${ }^{2}$, Costel Ceocea ${ }^{3}$, Aurel Mihail Țîțut, \\ ${ }^{1}$ Marquardt Schaltsysteme SCS, Sibiu, Romania \\ ${ }^{2} S C$ TECHNOCAD SA, 72, Vasile Alecsandri Street, Baia Mare, Romania \\ ${ }^{3}$ Vasile Alecsandri University of Bacău, 157 Mărăști Street, Bacău \\ ${ }^{4}$ Lucian Blaga University of Sibiu, 10, Victoriei Street, Sibiu, România \\ ${ }_{5}$ The Academy of Romanian Scientists, 54, Splaiul Independenței, Sector 5, Bucharest, Romania \\ E-mails:f.iuonas@outlook.com, danut.iuonas@yahoo.com, bianca.bontiu@gmail.com. \\ costelceocea@gmail.com, mihail.titu@ulbsibiu.ro
}

\begin{abstract}
Productivity and quality are among the objective functions which can be influenced by the flow rate and the state of the cooling channels of a plastic injection mold. The scientific work presents the place and the role of this subject in the machine building industry and its main purpose is to improve and clean the cooling channels using an acid cleaning device. Due to the hard water from Sibiu, in time inside the cooling channels of the injection mold a layer of rust is deposited, leading to a decrease in flow and temperature transfer to the inside of the mold. Following an analysis conducted within a company in the automotive field in Sibiu, a solution to this problem has been reached and implicitly to a remarkable improvement and an increase in the productivity of the plastic injection mold.
\end{abstract}

Keywords: Plastics Injection, Injection Mold, Cooling Channels, Productivity, Quality Improvement.

\section{Introduction}

The plastic injection mold is a high precision tool used for the production of plastic parts for different industries.

In the analyzed bibliographic materials, several works have been identified that address the issue of injection molds.

In Zabala's work [1], he deals with injection molding, which is actually a one-step manufacturing process, of plastic parts that have very precise dimensions and geometries and low roughness. His work presents an innovative approach that aims to simulate the behavior of plastics and materials in the laboratory, in order to minimize the costs associated with mold failures, by anticipating the life of the mold.

Jahan and his colleagues [2] propose a methodology for generating optimized configurations of cooling channel design in plastic injection molds.

Karyofylli [3] based on the premise that mold filling is an important stage of injection molding, which is one of the most used manufacturing processes for the production of thermoplastic components in large volumes, in his paper presents a numerical solution to a problem of filling the mold, using finite elements and then comparing the results with the experiments.
$\mathrm{Mi}$ and his colleagues [4] approached the methods of obtaining the high performance GF / iPP composites.

Park [5] studied the quality of the products obtained by molding, metal-colored plastic product and evaluated the process parameters; injection rate, injection pressure and pigment content and how the influence of the rapid cooling and heating system is felt.

Fernandez-Barranco et al. [6] studied the mechanical and crystallographic properties of Injection-Molded Polyamide 66 / Sepiolite Nanocomposites using different clay loading.

Other identified studies belong to Johnston [7] who designed an auxiliary process controller, implemented and validated it for the online process and for quality optimization. The objective function included terms related to process variation, model uncertainty and control energy.

Shamsuzzaman [8] presented in his study an optimization model for designing an exponentially weighted moving average (EWMA) scheme consisting of two individual EWMA schemes (called dual-EWMA schemes) for the purpose of efficient monitoring of a range of mean shifts in - an injection molding process that produces plastic parts.

Last but not least, $\mathrm{Wu}$ and collaborators [9] compared and analyzed surface and internal morphologies, fracture morphologies, cell structure and mechanical properties of the weld line area of 
the specimens obtained by injection molding with core-back foam and modeling conventional foam injection.

Starting from the aspects identified from the bibliographic study carried out, this paper will address the problem of cleaning the cooling channels of a plastic injection mold, and the starting point will be the description of the process of plastic injection, followed by the presentation components of the plastic injection mold.

\section{The Plastic Injection Process}

The plastic material is inserted into the feed tank, from where it is dosed and reaches the cylinder of the injection machine. Inside the work cylinder is a snail-piston, which, in the first phase of a work cycle rotates, which leads to the advance of the plastic material towards the front of the cylinder. As it advances, its plasticization also occurs, due to the fact that the cylinder is heated from the outside, with the help of electrical resistors placed on its circumference. When, in front of the piston snail, in the front of the cylinder, the amount of material required for an injection has accumulated, the piston snail acts as a piston, its advance is provided by a hydraulic system, therefore, the material is pushed under pressure in the mold.

After cooling the piece / parts the mold opens (the screw is withdrawn before opening the mold) allowing the injection of the injected part / pieces. The mold is then closed and the injection cycle is resumed.

The mold is composed of two parts:

- the movable part (this part is constantly moving transversely or vertically, depending on the machine it operates);

- the fixed part (this part is fixed to the clamping panel of the injection machine, either by means of the screws to be fixed through the threaded bores or by means of the fixing clamps).

The plan in which the molds are opened represents the separation plan.

The granular material is inserted into the injection machine screw, where at a certain melting temperature it is heated and injected into the plastic injection mold, respectively the nests of the mold. Due to the fact that the molten material has a temperature of approximately $280-300^{\circ} \mathrm{C}$ at the time of injection into the nest, the mold must maintain its constant temperature already set. In this sense there were cooling channels of the mold and nests.

The temperature of the plastic injection mold is one of the most important technological parameters that influence the quality of the injected product.

The entire process of injection of the plastic part can be carried out under optimum conditions only when the temperature of the mold is kept constant.
Cooling the injection molds is a necessity, as this process helps to reduce the injection cycle, increasing productivity, and getting parts injected with minimal contractions. The most commonly used cooling medium is water, the route of which is conducted in a closed circuit.

The temperature of the mold must meet the following two aspects:

- Quality of the injected part;

- Injection cycles with a shorter duration.

The temperature of the mold can be adjusted according to the flow of water, which flows through the cooling channels.

\section{Research Purpose}

This study was conducted on the reason of the very hard water from the water network of Sibiu Municipality. In time, inside the cooling channels of the injection molds of a Sibiu company, a strong rust layer was deposited. This layer of rust leads to the decrease of the possible water flow, but also to the thermal conductivity and the increase of the injection cycle.

The objective of this study is to highlight the influence of untreated water inside the mold and to find an optimal solution for removing the already deposited queen.

This process was implemented within a multinational company in the Automotive field.

\section{Analysis of the Flow from the Cooling Channels Before and After Cleaning Them with Acid}

This study was conducted and implemented within a multinational company and the action was carried out on 4 injection molds (100 - $300 \mathrm{~kg})$.

All molds went through the same process, same timing and the same acid cleaning machine was used.

The steps taken to carry out the process are presented below.

In the first phase, the mold is taken from the storage space and taken to the specially arranged place.

Before measuring the flow rate of the mold, this circuit should be blown with air to remove the water that has remained inside the mold and other unnecessary residues.

After each circuit has been cleaned individually and subsequently using the so-called connecting bridges, the entire circuit of the mold is blown.

After this the first action, with the help of a HB Therm-Temperiergeraet Thermo device (device used permanently for heating / maintaining / cooling the mold), the flow of each individual circuit is measured for 2 minutes.

After measuring the flow, the acid cleaning of the mold begins. 
The first step involves removing the remaining water inside the canals (because once the water comes in contact with the solutions used, it makes them no longer have the same properties).

For higher productivity, two Cleantower Optysystem 5000 devices are used, one for the moving part and one for the fixed part.

As stated above, a mold has several cooling circuits (for each plate separately). For a better result it was cleaned with acid, each plate separately. The required acid cleaning time (closed circuit) is 34 hours, depending on the size and stage of the mold.

Thus, after the acid cleaning of the circuit, the "Blow-out" option is activated, which with a certain pressure (bar) eliminates everything that comes off inside the channel after the acid cleaning has been performed.

Before treating the inside of the channels with a preservative solution, check the inside of the channels for possible micro pressures for 10 minutes.

If all is well and does not lose pressure then for 15 minutes a solution of preservation (in liquid form) is applied inside the channels.
After completing the process described above, using the same device (HB Therm), the flow rate for each channel is measured again.

Therefore, it can be seen in Figure 1, which is the flow rate for each channel. The nominal flow (the initial one at construction) was $5 \mathrm{l}$. This flow was measured for two minutes. The cooling channels are numbered as can be seen in Figure 1.

Thereby:

$$
\begin{aligned}
& \mathrm{E} 1-\mathrm{A} 1=4.4 \mathrm{~L} \\
& \mathrm{KA} 1-\mathrm{KE} 1=4.2 \mathrm{~L} \\
& \mathrm{~A} 2-\mathrm{E} 2=4.0 \mathrm{~L} \\
& \mathrm{~A} 3-\mathrm{E} 3=3.8 \mathrm{~L} \\
& \mathrm{~A} 4-\mathrm{E} 4=4.3 \mathrm{~L} \\
& \mathrm{KA} 2-\mathrm{KE} 2=4.3 \mathrm{~L} \\
& \mathrm{KA} 4-\mathrm{KE} 3=2.1 \mathrm{~L}
\end{aligned}
$$

One can also see the big difference of flow for each channel, if it is made at the nominal value. The biggest decrease is for the A3-E3 circuit, this being 1.21 .

Before starting the process, the total duration of the mold to warm up to temperatures of $80 \mathrm{oC}$ was timed. The temperature required to cool the mold injected to an exemplary quality.

This initial time was $4.32 \mathrm{sec}$, during which time the mold reached from $0 \mathrm{oC}$ to $80 \mathrm{oC}$.

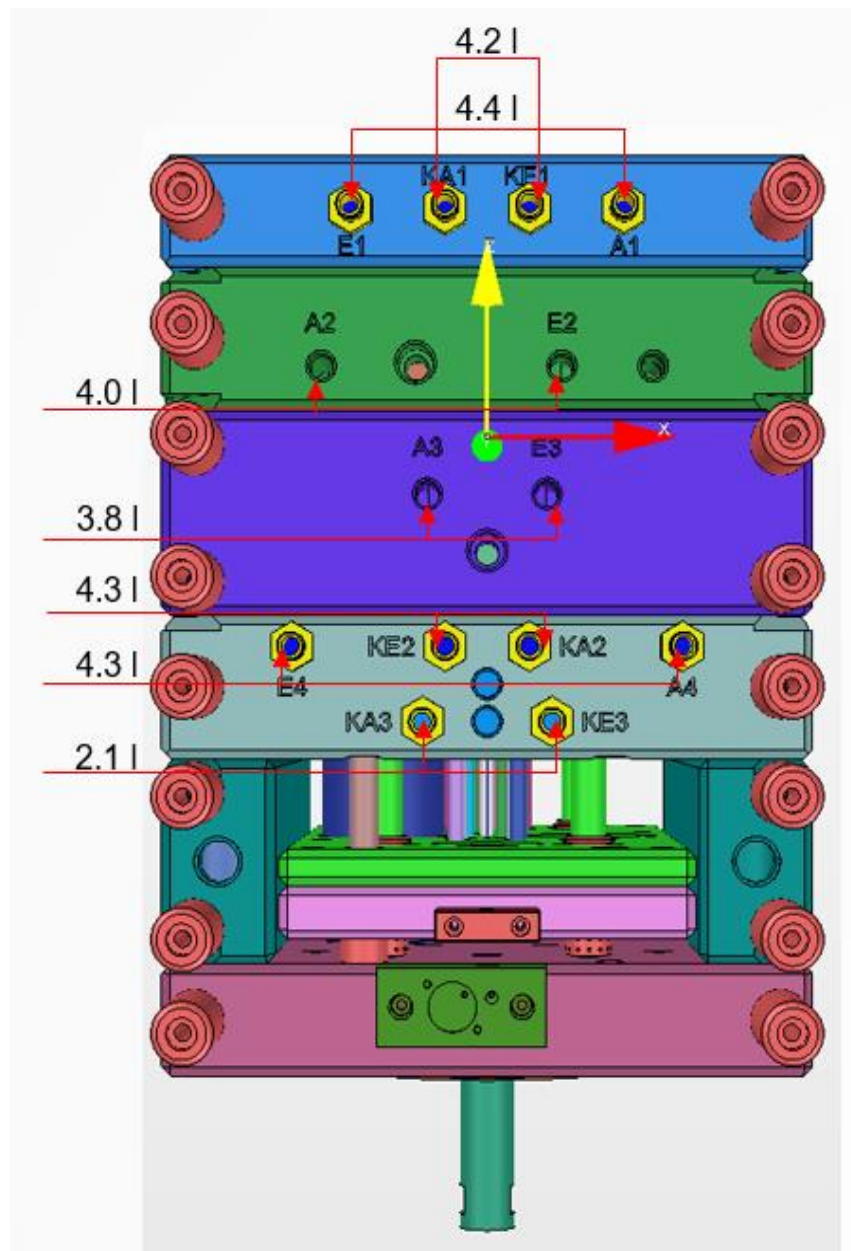

Figure 1: Flow of the cooling channels without cleaning it with acid 
Figure 2 shows the second flow measurement, after acid cleaning.

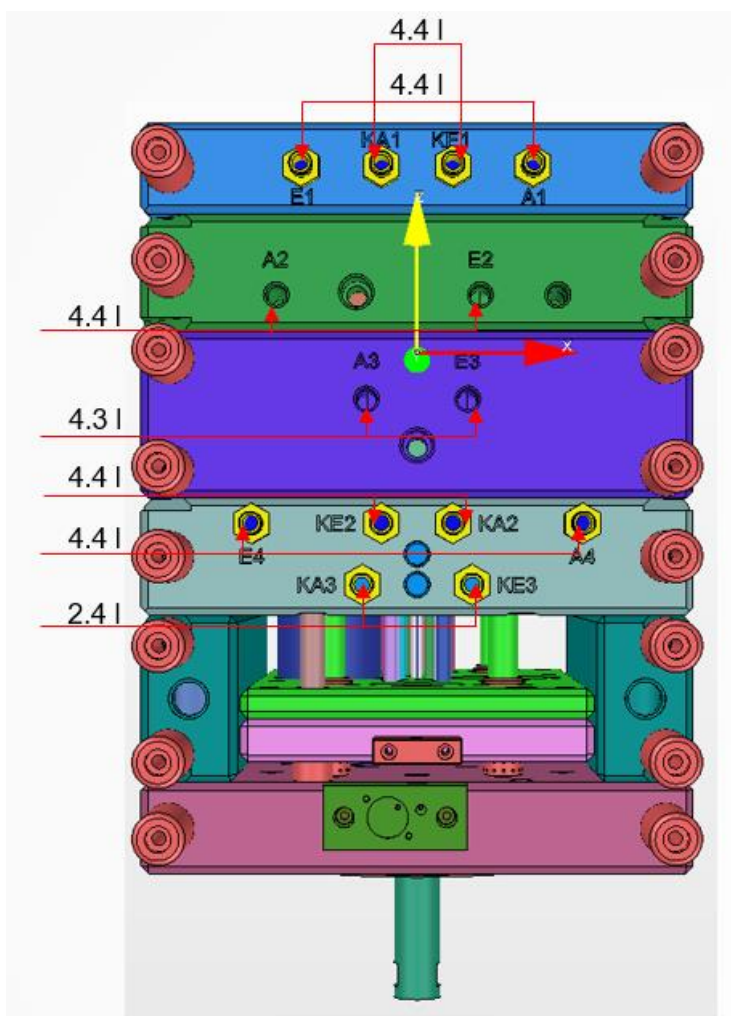

Thereby:

Figure 2: Flow of the cooling channels after the process

$$
\begin{aligned}
& \mathrm{E} 1-\mathrm{A} 1=4.4 \mathrm{~L} \\
& \mathrm{KA} 1-\mathrm{KE} 1=4.4 \mathrm{~L} \\
& \mathrm{~A} 2-\mathrm{E} 2=4.4 \mathrm{~L} \\
& \mathrm{~A} 3-\mathrm{E} 3=4.3 \mathrm{~L} \\
& \mathrm{~A} 4-\mathrm{E} 4=4.4 \mathrm{~L} \\
& \mathrm{KA} 2-\mathrm{KE} 2=4.4 \mathrm{~L} \\
& \mathrm{KA} 4-\mathrm{KE} 3=2.4 \mathrm{~L}
\end{aligned}
$$

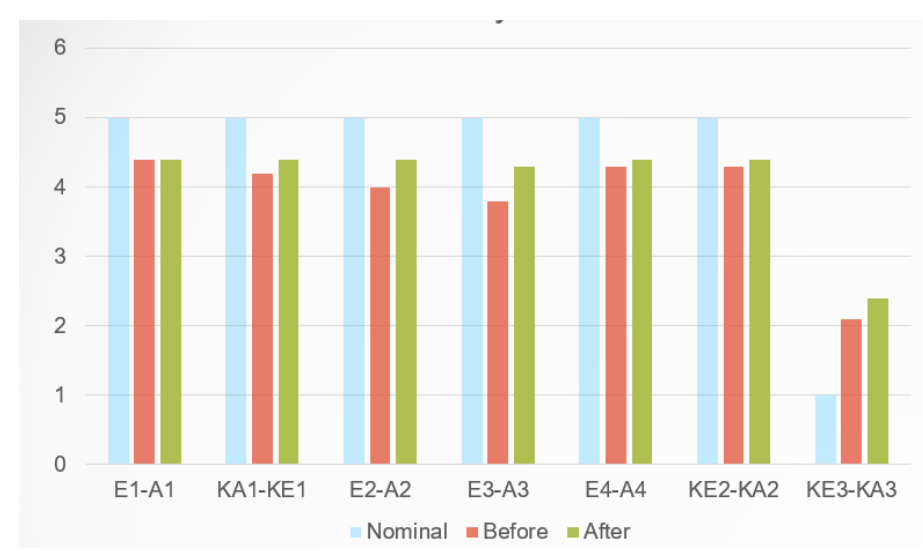

Figure 3: Differences between Nominal, Before and After

One can see in Figure 3, a diagram that highlights the differences encountered. The nominal flow is represented by the blue color and is the flow that the mold had when it was built.

The red color shows the flow that the mold had after injecting $4.8 \mathrm{Mil}$ pieces. Last but not least, the green color is highlighted by the final flow rate, i.e. after the cleaning process of the mold. The difference is visible.

The mold on which this analysis was performed was built in 2008 (Figure 4), and so far it has injected more than 4,800,000 pieces.

This proves that in about 10 years of permanent production, the mold has lost almost 11 of its flow. 


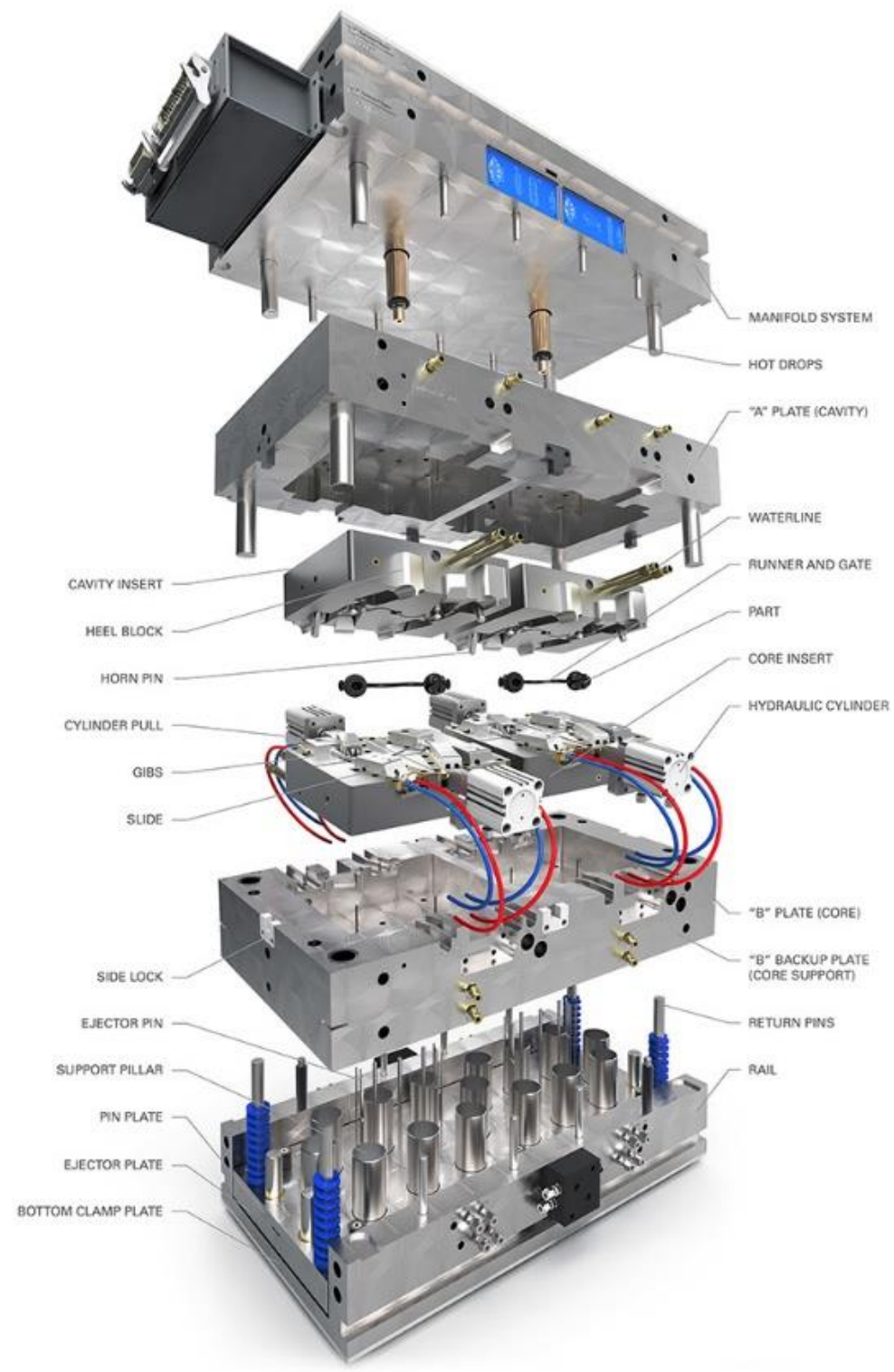

Figure 4: Anatomy of a mold, with all the plates visible

Using this method of cleaning, it was able to bring in an improvement of $0.5 \mathrm{l} / 2 \mathrm{~min}$ in $3 \mathrm{~h}$. The cooling time is influenced by many factors, the flow being one of them. Until now, rust deposited in these channels could not be removed, negatively influencing the mold and the production time.

Thus, the following analysis was performed:

The time required to bring the mold to the temperature of $80 \mathrm{oC}$, before acid cleaning was 4.32 $\min$.

The time required to bring the mold to a temperature of $80 \mathrm{oC}$, after acid cleaning is $4.01 \mathrm{~min}$.

Thus, it turns out that for the mold in this study, the improvement is $31 \mathrm{sec}$.

The current cycle time is $18.11 \mathrm{sec}$, which means that 1.71 cycles are obtained in addition to the initial, approximately 4 new injected tracks.
In the production area there are approximately 95 Arburg injection machines, it is assumed that:

It is possible to clean 50 molds out of the 95 possible ones.

With a gain of about $30 \mathrm{sec}$. in each mold, a production time of about 25 minutes is gained. With an injection cycle of approximately 19 seconds, 79 new cycles are gained. It is an improvement in productivity.

\section{The Needed Devices}

The devices used in this analysis are the following:

- Mobile crane for mold handling;

- HB Therm, Themperiergeraet;

- Cleantower Optisystem 5000;

- Air coupling and air gun. 


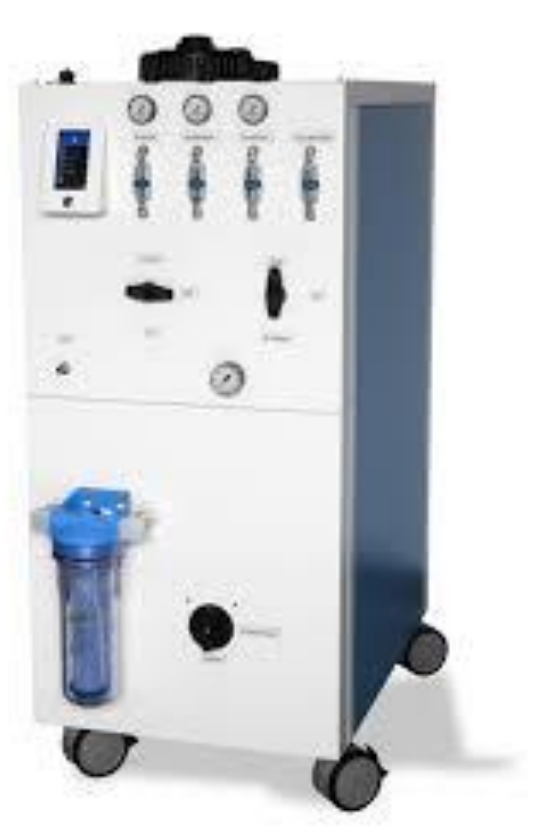

Figure 5: Cleantower Optisystem 6000

The Cleantower Optisystem 5000 (Figure 5) is an apparatus designed for cleaning and maintaining plastic injection molds.

It has 4 functions:

- Blow-Out - water cleaning of the mold;

- Pressure Test - checks the pressure and inspects for possible micro cracks;

- Rinses - acid cleaning of the ducts;

- Conservation - preservation of the cooling grooves.

The solutions used for cleaning are:

- Cleanpower 10;

- Cleanpower 30;

- Cleanpower 40.

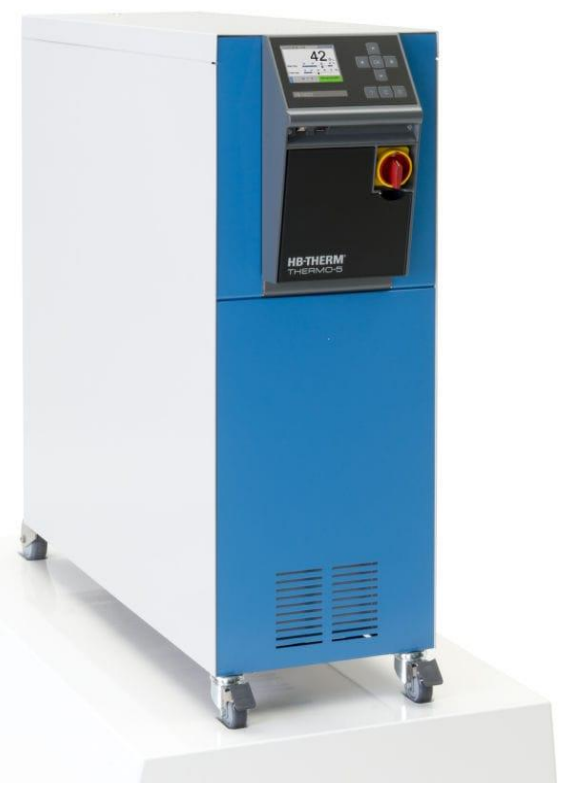

Figure 6: HB-Therm, Thermo 6, Themperiergeraet
This device is always used for heating / cooling / cleaning mold. The flow of the channels was also measured with this device, with excellent accuracy. An apparatus is used for the movable part and one for the fixed part of the mold.

\section{Conclusions}

The process of cleaning the cooling channels of a plastic injection mold is an essential one for extending the life of the mold.

The main factor that causes rust over time in the cooling channels is the water in the Sibiu area.

From the diagrams presented in this research it turned out that, over time, inside the cooling channels, a visible layer of rust was deposited with a special chamber.

The water in Sibiu is a very hard water, which in time bears the metal, thus leading to the deposited rust.

So far in the company analyzed is no solution to combat this, in the molds already affected.

Initially due to the lack of a well-established process, after the mold was stopped from production, to be stored in the storage tank, it was not completely cleaned by water. Water remaining in the mold for 3-4 weeks resulted in a strong rust layer.

Thus, this process is currently implemented globally, with very good results.

At the moment in parallel, we are trying to improve the water in the Sibiu area by applying different filters.

As a final conclusion, this process is a good one for fighting and maintaining the quality of the final piece.

\section{References}

[1] Zabala, Fernandez, X; Rodriguez, JC; LopezOrtega, A; Fuentes, E; Bayon, R; Igartua, A; Girot, $\mathrm{F}$, Mechanism-based wear models for plastic injection moulds, Elsevier Science Sa, Po Box 564, 1001 Lausanne, Switzerland, Wear, Volume: 440, Article Number: 203105, DOI: 10.1016/j.wear.2019.203105, Published:DEC 15 2019.

[2] Jahan, SA; El-Mounayri, H, A Thermomechanical Analysis of Conformal Cooling Channels in 3D Printed Plastic Injection Molds, MDPI, St AlbanAnlage 66, Ch-4052 Basel, Switzerland, Applied Sciences-Basel, Volume: 8 Issue: 12, Article Number: 2567, DOI: 10.3390/app8122567, Published:DEC 2018.

[3] Karyofylli, V; Behr, M; Schmitz, M ; Hopmann, C, Novel discretization methods for improved simulation precision in injection molding, WileyV C H Verlag Gmbh, Postfach 101161, 69451 Weinheim, Germany, Materialwissenschaft Und 
Werkstofftechnik, Volume: 48 Issue: 12 Pages: 1264-1269, DOI: 10.1002/mawe.201700156, Published:DEC 2017.

[4] Mi, DS; La, RX ; Wang, T; Zhang, XW ; Zhang, J, Hierarchic structure and mechanical property of glass fiber reinforced isotactic polypropylene composites molded by multiflow vibration injection molding, Wiley, 111 River St, Hoboken 07030-5774, NJ USA, Polymer Composites, Volume: 38 Issue: 12 Pages: 2707-2717, DOI: 10.1002/pc.23868, Published:DEC 2017.

[5] Park, YW; Lee, GS; Kwak, JS, A study on compound contents for plastic injection molding products of metallic resin pigment, Korean Soc Mechanical Engineers, Kstc New Bld. 7th Floor, 635-4 Yeoksam-Dong Kangnam-Ku, Seoul 135703, South Korea, Journal Of Mechanical Science And Technology, Volume: 30 Issue: 12 Pages: 5673-5677, DOI: 10.1007/s12206-016-1137-y, Published:DEC 2016.

[6] Fernandez-Barranco, C; Yebra-Rodriguez, A; La Rubia-Garcia, MD; Navas-Martos, FJ; AlvarezLloret, P, Mechanical and Crystallographic Properties of Injection-Molded Polyamide 66/Sepiolite Nanocomposites With Different Clay Loading, Wiley-Blackwell, 111 River St, Hoboken 07030-5774, NJ USA, Polymer Composites,
Volume: 36 Issue: 12 Pages: 2326-2333, DOI: 10.1002/pc.23146, Published:DEC 2015.

[7] Johnston, S; McCready, C; Hazen, D; VanDerwalker, D; Kazmer, D, On-Line Multivariate Optimization of Injection Molding, Wiley, 111 River St, Hoboken 07030-5774, NJ USA, Polymer Engineering And Science, Volume: 55 Issue: 12 Pages: 2743-2750, DOI: 10.1002/pen.24163, Published:DEC 2015.

[8] Shamsuzzaman, M; Haridy, S; Maged, A; Alsyouf, I, Design and application of dual-EWMA scheme for anomaly detection in injection moulding process, Pergamon-Elsevier Science Ltd, The Boulevard, Langford Lane, Kidlington, Oxford 0x5 1gb, England, Computers \& Industrial Engineering, Volume: 138, Article Number: UNSP 106132, DOI: 10.1016/j.cie.2019.106132, Published:DEC 2019.

[9] Wu, H; Zhao, G; Wang, J; Wang, G; Zhang, M, A kind of special weld lines with high specific strength and elongation obtained by core-back chemical foam injection molding, Budapest Univ Technol \& Econ, Dept Polymer Eng, Muegyetem Rkp 3, Budapest, H-1111, Hungary, Express Polymer Letters, Volume: 13 Issue: 12 Pages: 1041-1056, DOI: 10.3144/expresspolymlett.2019.91, Published:DEC 2019. 